\title{
A Critical Review on the Economics of Disasters"
}

\author{
$\mathrm{Xi} \mathrm{Yu}^{1,2}$, Yandong Tang ${ }^{1}$ \\ 1. Institute of Disaster Prevention, Sanhe Hebei 065201, China \\ 2. Institute of engineering mechanics, China Earthquake Administration, Haerbin Heilongjiang150090, China \\ E-mail:puyuxi@126.com
}

Received 30 November 2016

Accepted 24 January 2017

\begin{abstract}
The idea of economics of disasters can be traced back to the mid-19th century. The field of economics of disaster continues to be expand after 1970s and mainly concentrating in the disaster loss assessment methods, disaster economic impact model, the value of life assessments and disaster insurance and disaster risk securitization. This paper presents the research framework of economics of disasters, including disaster damage assessment, mitigation theory, disaster short-term economic impact, relationship between disasters and long-term economic growth, the value of life assessment, disaster risk management and disaster recovery and reconstruction theory.
\end{abstract}

Keywords: economics of disaster, loss assessment, value of statistical life, economic model

\section{Introduction}

Tsunamis, droughts, earthquakes, hurricanes and floods are a constant threat to society. These hazards affect human beings in many ways, for example, they can destroy houses, factories, buildings and infrastructures, and they can cause casualties, bring psychological damage, even destroy the ecological environment. Some disaster losses can be quantified in currency easily, such as the loss of housings, buildings. But some losses are difficult to evaluate in money, such as environmental disruption, mental trauma and inconvenience of life, etc. Although these losses is difficult to calculate statistically, there is a growing concern for the environment, health, safety, eco-systems and other related problems in post-disaster situations. Economics of disaster is a subdiscipline of economics that applied basic principles and methods of modern economics to study the economic relations between human society and disaster. It studies disasters from an economics' perspective and deals with problem that how to configure scarce resources under disaster conditions. It studies the economic relations between disasters and corporate, family or individual, relations between disasters and sectors of the economy, relations between disasters and macroeconomics.

\section{The origin of Economics of disasters}

Earlier research on economics of disasters is unsystematic. The idea of economics of disasters can be traced back to the late of 18th century. British economist Thomas Robert Malthus predicted that the rise in population would lead to widespread famine and catastrophe in his famous An Essay on the principle of population. John Stuart Mill argued that all traces of the mischiefs done by earthquakes, floods, hurricanes and war will disappear in a short period of time in his Principles of Political Economy with some of their

*Supported by Science and Technology Planning Project of Hebei Province, China (15275412)

the Fundamental Research Funds for the Central Universities（ZY20160103） 
Applications to Social Philosophy published in 1848. Mill though the perpetual consumption and reproduction of capital affords the explanation of what has so often excited wonder, the great rapidity with which countries recover from a state of devastation ${ }^{[1]}$. Almost a century later, John Kenneth Galbraith corroborated Mill's observations. He investigated the impact of Allied bombing raids of Hamburg and concluded that the raids had had little impact ${ }^{[2]}$.

With continued population growth and rapid economic development since the 1950s, industrial waste and pesticide pollution has become increasingly serious, which raised human awareness of environmental protection. Arthur Cecil Pigou developed Alfred Marshall's concept of externalities and used it to analyze environmental disasters, such as air and water pollution. Pigou argued that the existence of negative externalities is sufficient justification for government intervention. He advocated a tax, now called Pigovian taxes, on such activities to discourage them. Ronald Harry Coase suggested that well-defined property right could overcome the problem of externalities. Coase theorem states that if trade in an externality is possible and there are no transaction costs, bargaining will lead to an efficient outcome regardless of the initial allocation of property rights.

Jack Hirshleifer was the first economist that studied disasters deeply, He analyzed the choices people make in times of disaster and conflict to explain the possibilities and limits of human cooperation under severe environmental pressure ${ }^{[3]}$. Howard Kunreuther, a professor of Wharton School of the University of Pennsylvania, published an article entitled The Alaskan earthquake: A case study in the economics of disaster in 1966. The term economics of disasters was used for the first time in this paper ${ }^{[4]}$. In 1967, Kunreuther, conducted an empirical analysis to study the price changes of emergency supplies in The peculiar economics of disaster. He concluded that most supply and demand problems facing an area hit by a natural disaster are generally short-run in nature because of the aid forthcoming from outside regions. Even when the threat of shortages does exist, the concern of residents in the community for the plight of others helps to minimize serious problems during the emergency period. These short-term response patterns indicate that sociological and psychological factors change to utility functions of residents during the short-run period and thus explain why economic behavior following a disaster appears at first glance to be somewhat peculiar ${ }^{[5]}$. Dacy and Kunreuther published the book The Economics of Natural Disasters: Implications for Federal Policy on the basis of previous studies in 1969, following the National Flood Insurance Act of the UnitedStates in 1968 and devastating losses from the Alaska earthquake in 1964 [6]. In this book, the authors claimed that the main objective of the book is "to formulate a clear-cut case for the development of a comprehensive system of disaster insurance as an alternative to the current paternalistic Federalpolicy" ${ }^{[6]}$. Some others, for example, Sorkin( 1982) and AlbalaBertrand (1993), aim to offer the generalized framework of disaster analysis, but they are yet oriented to investigate empirical cases and/or to provide the empirical modeling frameworks for the analysis, and lack the theoretical development and/or analysis of disasters and their impacts to economy ${ }^{[7,8]}$.

In China, the well-known economist Yu Guangyuan first pointed out the importance of studying disaster from an economic point of view in the 1980s. Subsequently, Zheng GongchengHe Aiping and Tang Yandong published their works to discuss the basic principles of economics of disasters, and initially establish a theoretical framework ${ }^{[9-11]}$. In addition, many scholars have also published papers to discuss the issue related to economics of disasters ${ }^{[12-15]}$.

\section{Recent advances in Economics of Disasters}

The economics of natural disasters has gotten initial development during the 1970s. The research is heavily focused on the direct economic losses assessment or business interruption losses evaluation caused by hazards. In the 1990s, the research of this field have developed and deepened. The content of economics of disasters research is enriching and extending from direct loss to indirect loss, economic effect models, value of statistical life, recovery theory and disaster risk management. The research method has also reached an unprecedented level of innovation. These researches mostly concentrated in the disaster loss assessment, risk analysis, value of life assessments, hazard insurance and disaster risk securitization. 


\subsection{Disaster Loss Assessment}

Timely and accurate assessment of losses caused by disasters can help us to determine disaster spatial extent, severity and distribution of loss, affected object and proportion. It's very importance for emergency rescue, recovery and risk management. In addition, loss prediction is the foundation to determine risk severity and type in risk analysis.

Research focuses on basic concepts of disaster loss and loss assessment framework proposed by international organizations, countries, institutions or scholars. National Research Council of US completed a report The Impacts of Natural Disasters: A Framework for Loss Estimation in $1999^{[16]}$.In order to standardize the methods and process of loss assessment, Economic Commission for Latin America and the Caribbean published report: Manual for Estimating the Socioeconomic Effects of Natural Disasters ${ }^{[17]}$ and the organization revised the report in 2003. The revised one entitled Handbook for Estimating the Socio-Economic and Environmental Effects of Disasters ${ }^{[18]}$. In these two handbooks, the basic concepts, methods of disaster losses and sectors damage assessment method are described.

\subsubsection{Direct and Indirect Loss}

Distinction of direct and indirect losses seem to be simple, in fact, it is a controversial problem. Some scholars distinguish direct and indirect losses based on the relationship between losses and hazards or on the chronological sequence ${ }^{[1]}$. Such as, Cochrane (2004) argued that direct loss is a loss linked directly to disaster, indirect loss is any loss other than direct loss. Some scholars believe that direct losses are losses that occur on the spot of disasters. These are not valid criterion for distinguishing them. For example, earthquake destroyed the gas pipelines, gas exploded and burned buildings. The damage of buildings linked earthquake indirectly, but the loss should be direct loss. Economics, business, accounting, and related fields often distinguish between quantities that are stocks and those that are flows. A stock variable is measured at one specific time, and represents a quantity existing at that point in time. A flow variable is measured over an interval of time. Many economists believe that the distinction between direct and indirect losses should be based on the principle of the stocks and flows. Direct losses relate to the damage to the stock of capital assets, including building, infrastructure, industrial plants, machinery equipment, and inventories of finished, intermediate, and raw materials destroyed by hazards. Property damage represents a decline in stock value and usually leads to a decrease in service flows. Indirect losses refer to damage to the flow of goods and services including lower output of business interruption, and the increased costs associated with the use of more expensive inputs because of the destruction of cheaper usual sources of supply.

Adam Rose disagrees the view of stocks and flows. He suggests that the value of an asset is the discounted flow of net future returns from its operation. So the measures both stocks and flows represent the same things, including both would involve double-counting. Rose argues that flow measures are superior to stock measures and proposes the use of the term "higher-order effects". This point of view is suitable for overall equity that can produce cash flow. We cannot calculate the flow of a simple equipment, such as computer, transport vehicle, and weld equipment, because they cannot produce output alone.

A secondary disaster caused by a specific hazard can also damage property that pertains to direct losses, for example, earthquake destroyed the gas pipelines, gas exploded and burned buildings. The damage of buildings is a part of direct losses. So direct losses consist of two more refined types of losses. Primary direct losses are those resulting from the primary hazard, such as shake damage from an earthquake or water and wind damage from a hurricane. Secondary direct losses are those additional impacts resulting from secondary disasters, such as the building burned by fire following an earthquake (Fig. 1). For example, more than half of the 700 thousands buildings destroyed in Great Kanto Earthquake in 1923 were damaged by fire.

Indirect losses are the losses of flow. Primary indirect losses are induced by a company's own property damage by primary or secondary disasters, for example, lost production stemming from direct losses of factories, equipment, and instruments. Primary indirect losses relate to business interruption, which means a flow. The extent of primary indirect losses does not stop here, but sets off a chain reaction. Lower production of a factory may affect the output of other factories through forward and backward linkages. We can use the concept of linkage indirect losses to distinguish them from primary indirect losses (Fig. 2). 


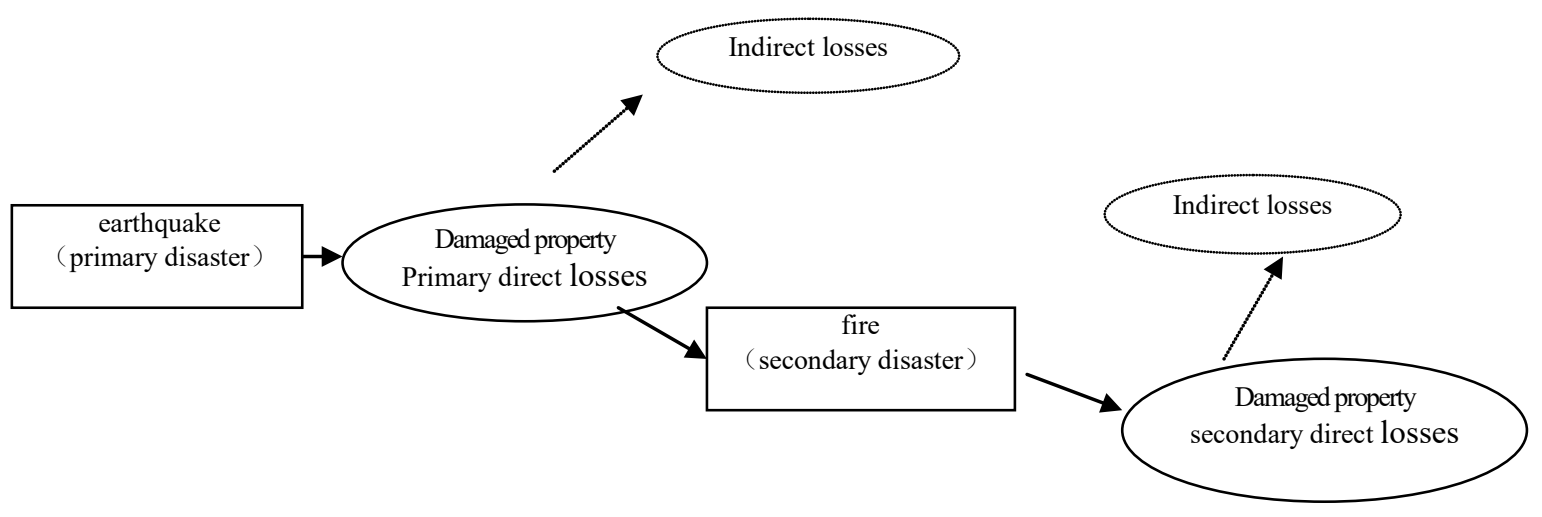

Fig. 1. Primary Direct Losses and Secondary Direct Losses

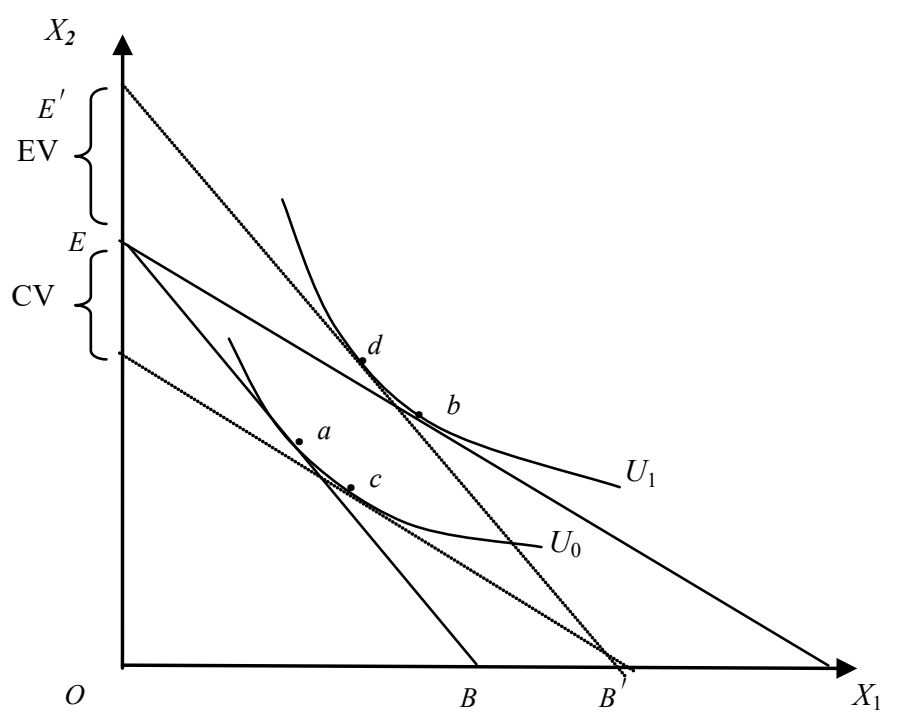

Fig. 2. compensating variation $(\mathrm{CV})$ and Equivalent variation (EV)

\subsubsection{Economic Assessment Indices}

Hazards can destroy the infrastructure, such as transportation, water supply, power supply, communication system, hamper the normal operation of society, and deteriorate human living environment. Hazards affect people's welfare by influencing the level of utility. Therefore, the measure the disaster loss may be changed into welfare changes. On the one hand, the disasters may change the supply or demand of the commodities, then the price change can affect the welfare of the people. On the other hand, people's income levels can decrease caused by hazards. In addition, the disasters have an effect on the quantity or quality of some market/ non-market goods, such as quality of water, traffic, air quality. So welfare economics provides the theoretical basis of the disaster damage assessment. Indicators to measure the welfare changes include consumer surplus (CS) and producer surplus (PS), compensating variation (CV) and equivalent variation (EV), compensation surplus (cs) and equivalent surplus (ES) ${ }^{[11]}$.

At the background of economics of disasters, compensating variation refers to the amount of additional money a consumer would need to reach its initial utility after a change in prices after disasters. 
Equivalent variation is a measure of how much more money a consumer would pay before a price increase to avert the price increase (Fig. 2). Where $E B$ and $E B^{\prime}$ are the old and new budget lines before and after the change in price. $U_{0}$ and $U_{1}$ are the old and new utility levels respectively.

$\mathrm{CV}$ and $\mathrm{EV}$ can be defined by the solution of indirect utility function as follows.

$$
\begin{aligned}
& V\left(P_{1}, P_{2}, Y\right)=V\left(P_{1}^{\prime}, P_{2}, Y-C V\right)=U_{0} \\
& V\left(P_{1}, P_{2}, Y+E V\right)=V\left(P_{1}^{\prime}, P_{2}, Y\right)=U_{1}
\end{aligned}
$$

Where $V\left(P_{1}, P_{2}, Y\right)$ is indirect utility function, $\mathrm{Y}$ is income, $P_{1}$ and $P_{2}$ are the prices of the two goods, $P_{1}{ }^{\prime}$ is affected price of goods one by disasters.

For the price change caused by disasters, compensating variation is simply the area under the Hicksian demand curve evaluated at the initial utility level and the two prices. Similarly, equivalent variation is simply the area under the Hicksian demand curve evaluated at the new utility level and the two prices. Fig. 3 depicts these two measures for the price change.

$$
\begin{aligned}
& C V=\int_{P_{1}^{\prime}}^{P_{1}} \frac{\partial e\left(P_{1}, P_{2}, U_{0}\right)}{\partial P_{1}} d P_{1}=\int_{P_{1}^{\prime}}^{P_{1}} x_{1}^{h}\left(P_{1}, P_{2}, U_{0}\right) d P_{1} \\
& E V=\int_{P_{1}^{\prime}}^{P_{1}} \frac{\partial e\left(P_{1}, P_{2}, U_{1}\right)}{\partial P_{1}} d P_{1}=\int_{P_{1}^{\prime}}^{P_{1}} x_{1}^{h}\left(P_{1}, P_{2}, U_{1}\right) d P_{1}
\end{aligned}
$$

Where $e\left(P_{1}, P_{2}, U_{0}\right)$ is expenditure function at utility level $U_{0}$, and $x_{1}{ }^{h}$ is Hicksian demand function.

The relation of three indices $C V, C S$ and $E V$ is as follows.

$$
\begin{aligned}
& C V=A \\
& C S=A+B \\
& E V=A+B+C
\end{aligned}
$$

When consumers can choose the purchase of the two commodities freely, they will choose the quantities of two goods determined by the point of tangency of the budget line and indifference curve to reach maximum utility. However, in some cases, consumer cannot choose goods freely, for example, under the condition of shortage of foodstuffs after disasters, and the utility maximization conditions will change. The quantity of goods determined by the point of intersection of budget line and indifference curve will be chosen. Compensating surplus and equivalent surplus can be used in these cases. These two measurements are closely related to the compensating variation and equivalent variation respectively. The only difference is the restriction on adjusting the purchase of goods.

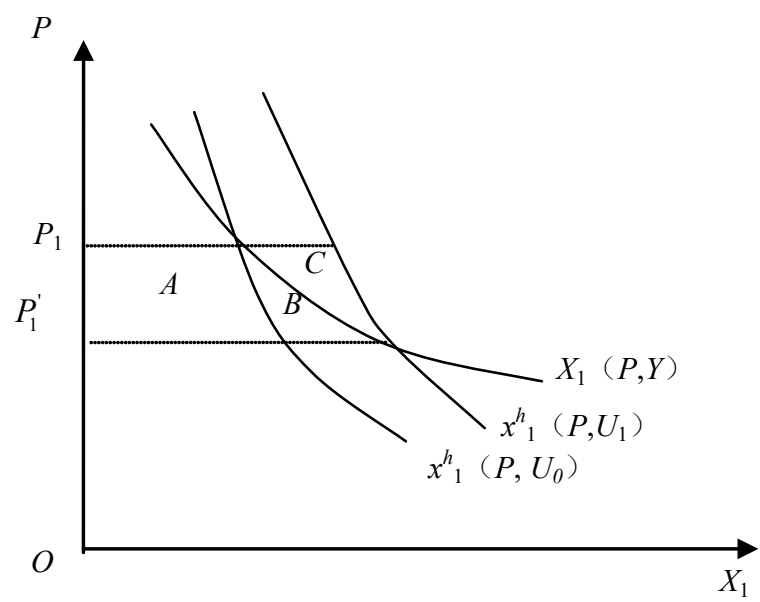

Fig. 3. The relation of $C V, C S$ and $E V$

\subsubsection{Disaster Economic Impact Model}

Since the pioneering work of Dacy and Kunreuther and Cochrane, significant progress has been made in recent years for economic analysis of natural disasters, especially in the field of modeling economic impacts of disasters in a regional context. The recent advancements focus on empirical analysis and modeling extensions and modifications to fit them to disaster situations. Many problems remain unsolved, such as the treatment of time, space, and counteractions. Input-Output (I-O) Model, Social Accounting Matrix (SAM), Computable General Equilibrium (CGE) model and econometric models are widely adopted to estimate indirect loss caused by various hazards.

I-O model may be the most widely used model framework to estimate natural and manmade disasters (Cochrane, 1974, 1997; Wilson, 1982; Kawashima et al., 1991; Boisvert, 1992; Gordon and Richardson, 1996; Rose et al., 1997; Rose and Benavides, 1998; and Okuyama et al., 1999). As early as 1974, Harold Cochrane used the model to assess the earthquake damage. Assessment of the man-made disasters can be traced back to the strategic bombing in World War II and extend to the World Trade Center terrorist attacks. The U.S. Federal Emergency Management Agency and the U.S. National Academy of Building Research jointly developed HAZUS loss assessment system also use input-output method to assess the indirect losses. The 
main reason that input-output model is popular is that it can reflect the regional economic interdependence within the relationship. Furthermore, the model is relatively simple and easily modified and integrated with other models. The simplicity of the IO model creates a set of weaknesses, including its linear structure, its rigid coefficients, no supply capacity constraint, no response to price change, a lack of explicit resource constraints. Because of this, it is generally believed that the model will overestimate the impact caused by disasters.

Although these limitations of IO model, a number of scholars have utilized and improved it to assess disaster indirect loss. In recent years, social account matrix (SAM), lagging the expenditure model, inter-industry time-series model (SIM) and the regional econometric input-output model (REIM) have been developed based on basic input-output model ${ }^{[24]}$.

Computable general equilibrium model (CGE) was developed because of the defects of input-output model. CGE model overcomes some of the shortcomings of the input-output method, it is non-linear, can resolve the interaction between quantity and price and it take into account resource constraints, the utility maximization problem. CGE model can simulate external shocks on the economy ${ }^{[25]}$.

\subsubsection{Nonmarket Effects Evaluation}

Disasters can cause a variety of effects. Some of them have market price and can be traded in the market, such as property loss, income reduction and yield decline. Some impacts, called 'nonmarket effect', are particularly challenging to value in monetary terms because their very nature is difficult to measure and quantify. Examples of nonmarket effect include death and injury, environmental damage, damage to cultural artifacts, and losses of memorabilia (photographs, books, toys and personal original work). Non-market impact caused by disasters does not have market value, its value cannot or difficult to be measured in the market. There are, however, a variety of non-market valuation methods that can be used to assess the value people attribute to nonmarket natural disaster impacts. Care is needed when using these methods to estimate the value of disaster impacts, as they can be complicated and time-consuming. If the methods are beyond the time and resource capacities available, simply list the important nonmarket effect of a natural disaster in as much detail as possible.

We will start simply with the most obvious, most easily valued impacts. This may mean looking for impacts resulting in changes in productivity that can be valued using market prices. River pollution may disrupt a traditional downstream fishery or some agricultural activity. The net change in fish or crop production can be identified and valued. The change in the quality of water flowing downstream and its effect on the coastal mangroves or on offshore coral reefs is a secondary effect. Secondary effects may be very important, both ecologically and economically, but the analyst would do best to start with the fishery or the agricultural activity.

The other two categories of non-market valuation methods are known as 'revealed preference methods' and 'stated preference methods'. Revealed preference methods include defensive expenditure approach, hedonic price method and travel cost approach. These methods estimate the environmental and other nonmarket products by observing people's market behavior, to "expressed preferences". The principal difference between revealed preference and stated preference methods is that the latter draw their data from people's responses to hypothetical questions rather than from observations of real-world choices. Stated preference methods gained popularity after the two major non-use values, namely, option and existence values, have been recognized as important components of the total economic values in environmental economics literature, especially during the 1960s. While the conventional revealed preference method cannot assess these non-use values (Smith, 1993), the only method that is identified for estimating these values is the stated preference method. This method elicits willingness to pay (WTP) information that cannot be inferred from markets. The contingent valuation method (CVM) is a widely used nonmarket valuation method especially in the areas of environmental cost-benefit analysis and environmental impact assessment. Hence, a considerable amount of studies on CVM have emerged in the economic valuation literature, including a large number of studies criticizing the CVM method. The criticism revolves mainly around two aspects, namely, the validity and the reliability of the results, and the effects of various biases and errors. Table 1 shows the three nonmarket impact valuation methods and disaster impact can be assessed. 
Table 1. Nonmarket Impact Valuation Methods

\begin{tabular}{|c|c|c|c|}
\hline & \multicolumn{2}{|c|}{ Methods } & Disaster impact \\
\hline \multirow{5}{*}{ Market method } & \multicolumn{2}{|c|}{ Changes in productivity } & Productivity \\
\hline & \multirow{2}{*}{\multicolumn{2}{|c|}{ Replacement/restoration costs }} & Capital assets \\
\hline & & & Natural resource \\
\hline & \multicolumn{2}{|l|}{ Cost of illness } & Health(mortality) \\
\hline & \multicolumn{2}{|l|}{ Human capital } & Health(mortality) \\
\hline \multirow{4}{*}{$\begin{array}{l}\text { revealed preference } \\
\text { method }\end{array}$} & \multicolumn{2}{|c|}{ Preventive expenditures } & $\begin{array}{l}\text { Health, productivity, capital assets, natural } \\
\text { resource }\end{array}$ \\
\hline & \multirow{2}{*}{$\begin{array}{l}\text { Hedonic Price } \\
\text { Method }\end{array}$} & \multicolumn{2}{|c|}{ Hedonic Property Pricing Method Environmental quality } \\
\hline & & Hedonic Wage Method & Health \\
\hline & Travel cost me & & Natural resources \\
\hline \multirow[t]{2}{*}{$\begin{array}{l}\text { stated preference } \\
\text { methods }\end{array}$} & \multicolumn{2}{|c|}{ Contingent valuation method } & $\begin{array}{l}\text { Health } \\
\text { natural resources }\end{array}$ \\
\hline & \multicolumn{3}{|c|}{ Choice modeling method } \\
\hline
\end{tabular}

\subsection{Value of Statistical Life}

As early as the late 1970s and early 1980s, there is literature to assess the value of statistical life in the United States. But policy makers used human capital approach to calculate the income loss to assess the value of human life and thought it is immoral to assess the value of life. This continued until the Reagan administration. Human capital approach makes economic sense when how much compensation should pay for dependents in wrongful death settlements. But it is incorrect in principle because it ignores the individual's own welfare, preference, and WTP and it defines VSL in a narrow way.

Viscusi used WTP to assess the risk reduction benefit in cost-benefit analysis of an expensive regulation firstly. From then on, WTP approach has been accepted to estimate the value of a statistical life by scholars rapidly ${ }^{[19-22]}$.Individuals make decisions every day that reflect how they value health and mortality risks, such as driving an automobile, smoking a cigarette, crossing the street. Many of these choices involve market decisions, such as the purchase of a hazardous product or working on a risky job. Using evidence on market choices that involve implicit tradeoffs between risk and money, economists have developed estimates of the value of a statistical life
(VSL). VSL is the marginal willingness to pay (MWTP) for a small reduction in the probability of death during a given period or how much compensation that individual would require to accept a small increase in that probability. In fact, the MWTP is also the marginal rate of substitution (MRS) between goods and risk of death, as follows:

$$
V S L=M W T P=M R S_{\pi, w}=\lim _{\Delta \pi \rightarrow 0} \frac{\Delta P}{\Delta \pi}=\frac{d P}{d \pi}
$$

Where $P$ is payment, $\pi$ is the probability of death.

If a person is willing to spend $\$ 100$ to reduce the ten-thousandth of the probability of death suffering from hepatitis $\mathrm{A}$, then the value of his life will be one million dollar.

Assume that an individual obtains utility from wealth, the utility of death is zero, the state-dependent expected utility is

$$
E(u)=(1-\pi) \cdot u(w)
$$

Where $\mathrm{w}$ is wealth or income, $u(w)$ is utility to consume wealth w.

We can obtain an expression for the individual's VSL, as follows

$$
V S L=\frac{u(w)}{(1-\pi) M U(w)}
$$

Where $M U(\mathrm{w})$ is marginal utility. 
Equation 2 shows that individuals' marginal willingness to pay depends on their wealth and survival situation. All other things being equal, the rich have higher total utility and lower marginal utility and then they have higher VSL. Another results is that the higher the risk of death is, the higher will be the marginal willingness to pay to reduce the mortality risk.

Some scholars argue that assessing the value of life violates ethical because life is priceless. But if human life is priceless, all the mitigation measures regardless how expensive are worth taking. Such an assertion does not make sense economically. Under realistic conditions, we have to make trade-offs between changes

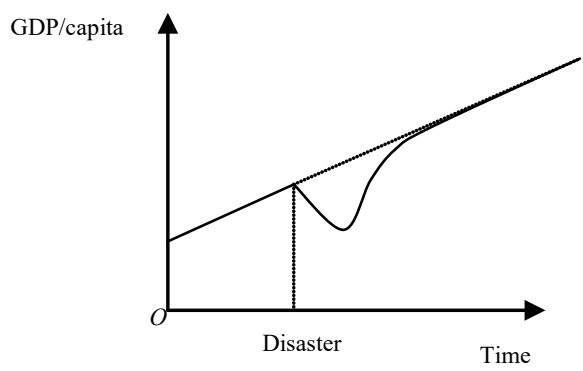

(a)

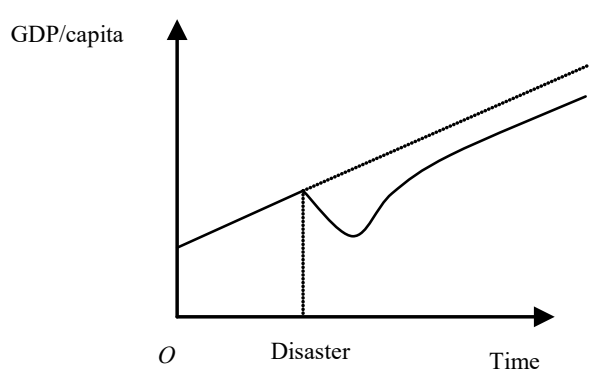

(c) in the probability of death and other goods that have monetary values in decision making. VSLs are often used in cost-benefit analysis; but they are not a measure of what is "lost" when a person dies. What people "buy" and "sell" is small changes in the probability of dying and is not life or death. The economic approach of VSL avoids the issue of valuing life. VSL focuses on risk.

The concept of VSL is very easy for us to associate it with compensation for deaths. Some scholars believe that the estimates of VSL can become the basis of compensation for wrongful deaths. In fact, this is a misconception because the concept cannot applied under conditions of certainty.

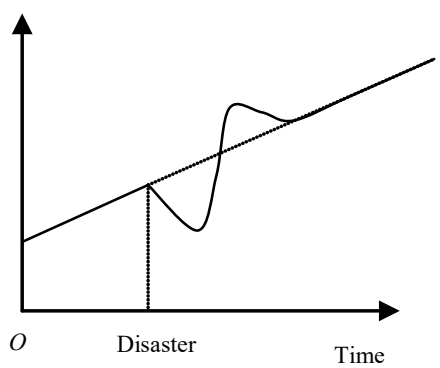

(b)

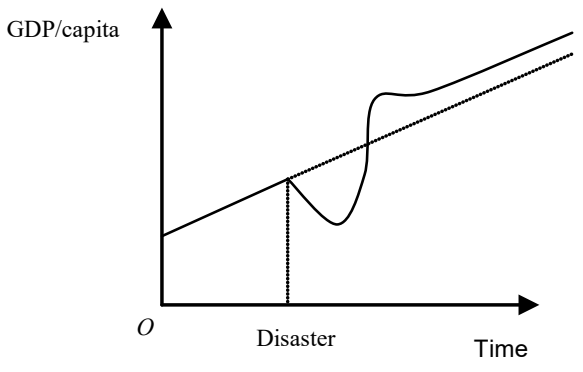

(d)

Fig. 4. Possible Long-run Impact of a Disaster on GDP per Capita

\subsection{Disaster and economic growth}

An important research question is relations between disasters and long-term economic growth. This question has been investigated empirically and theoretically by, e.g., Albala-Bertrand (1993), Benson (2003), and Skidmore and Toya (2002), Hallegatte and Dumasa (2009), but results are not conclusive. Albala-Bertrand (1993) found, in a statistical analysis of 28 disasters from 1960 to 1976 in 26 countries, that the long-run growth rate is unaffected by natural disasters. Benson (2003) carried out an analysis on 115 countries and found that the growth rate was lower in the countries that experienced more disasters. The analysis of Skidmore and Toya (2002) shows that climatic disasters are positively correlated with economic growth, whereas geologic disasters are negatively correlated with growth.

The report of the World Bank show that the growth rate can be like these (Fig. 4). 


\subsection{Disaster Insurance and Catastrophe Risk Securitization}

In the past few decades, our understanding of the extreme events or natural disasters has been greatly improved. Natural disaster management system including hazard map, building codes, the government emergency response to natural disaster management system, commercial insurance, has played an increasingly important role in disaster prevention and reduction of losses. Risk transfer financing methods include insurance financing and non-insured financing. Insurance is an economic institution that allows the transfer of financial risk from an individual to a pooled group of risks by means of a two-party contract. Aware of insurers' need for more capacity to finance catastrophe risk, entrepreneurs have been devising solutions that would spread catastrophe risk to investors by "securitizing" it. That is, entrepreneurs have been developing means of packaging insurers' catastrophe risk as securities that could be sold to investors. Such solutions, however, will only be successful if they simultaneously meet insurers' need to spread risk efficiently while offering investors opportunities to improve the performance of their portfolios. The securitization of catastrophe risk has taken several forms, each with advantages and disadvantages. Primary insurers can use all of the forms of securitizing insurance risk to supplement traditional reinsurance, and reinsurers can use them to supplement traditional retrocessions. Large self-insureds may also be able to use securitization to share their catastrophe risk with investors. To date, the principal forms of securitization include contingent surplus notes, catastrophe or "Act of God" bonds, and exchange traded catastrophe options.

\section{Conclusion}

The theoretical discussion and analysis of disaster is important to advance our knowledge for the impacts and consequences of a disaster. The new and special discipline of economics of disasters is in establishment and progress has been made in it's basic law, research methods and contents. The main areas of research are as follows:

(1) Disaster loss assessment methods

(2) Theory of value of statistical life

(3) Disaster economic impact model

(4) Disaster insurance and catastrophe risk securitization
In addition, many researchers have studied the longterm effects of disasters on economic growth, but there is no consistent point of view. Some scholars believe that disaster will lead to long-term negative economic effects, such as the slow economic growth, debt raising, area income gap increasing ${ }^{[26]}$. Some scholars support that disasters will not have a long-term effect on the economy. Recovery and reconstruction measures postdisaster can even increasing productivity, thus beneficial to the long-term development of the economy ${ }^{[27-30]}$. The current economic theory does not give a clear conclusion.

\section{References}

1. Mill J S. Principles of political economy with some of their applications to social philosophy. London: J.W. Parker, 1848

2. William B. The Economics of Natural and unnatural disasters. Michigan: WE Upjohn Institute, 2010.

3. Hirshleifer J. Economic behaviour in adversity. Chicago: The University of Chicago Press, 1987.

4. Kunreuther H, Fiore E S. The Alaskan earthquake: A case study in the economics of disaster[R]. 1966.

5. Kunreuther H. The peculiar economics of disaster. Public Choice. 1967, 3 (1): 67-83.

6. Dacy DC, Kunreuther H. The economics of natural disasters: Implications for federal policy. New York: the Free Press, 1969.

7. Sorkin A L. Economic aspects of natural hazards. Lexington, MA: Lexington Books, 1982.

8. Albala-Bertrand J M. Political Economy of Large Natural Disasters: With Special Reference to developing countries. Oxford: Oxford University Press, 1993.

9. Zheng GongchengThe Economics of Disasters. Changsha: Hunan People's Publishing House, 1998.

10. He Aiping. The Economics of Disasters. Xi'an: Northwest University Press, 2001.

11. Tang Yandong. The Economics of Disasters. Beijing: Tsinghua University Press, 2011.

12. WANG Yan-yan, LIU Shu-kun. Disaster Economic Research.Joural of Catasrtophology, 2005, 20 (1): 104109.

13. Xu Juan. Mitigation investment and the cost of disaster economics. Disaster of 2006, 21 (2): 103-105.

14. He Aiping developing countries, disasters, economic characteristics, causes and countermeasures. Disaster science 2000, 15 (2): 91-96.

15. Zhang Xiandong, Mei Guangqing Review on economics of disaster. Joural of Catasrtophology 1998, 13 (4): 81-87.

16. National Research Council (NRC). The impacts of natural disasters a framework for loss estimation. Washington, DC: National Academy of Sciences Press, 1999. 
17. United Nations. Economic Commission for Latin America and the Caribbean, World Bank. Manual for estimating the socio-economic effects of natural disasters, 1991.

18. United Nations. Economic Commission for Latin America and the Caribbean, World Bank. Handbook for Estimating the Socio-Economic and Environmental Effects of Disasters. New York: United Nations Publications, 2003.

19. Viscusi WK, Aldy J E. The value of a statistical life: a critical review of market estimates throughout the world. Journal of Risk and Uncertainty. 2003, 27 (1): 5-76.

20. Mei, Lu Yumei. The value of human life assessment methods.China Safety Science. 2007, 17 (3): 56-61.

21. Tang Yandong, LIU Chun-ping, Assessment of the value of life and death compensation, China Safety Science. 2010, 20 (4): 14-21.

22. Yu Xi Tang Yandong, LIU Chun-ping, and other disasters of life valuation theoretical studies.China Safety Science. 2009, 19 (12): 17-22.

23. Okuyama Y, Chang S. Modeling spatial and economic impacts of disasters. Berlin: Springer Verlag, 2004.
24. Okuyama Y, Chang S. Modeling spatial and economic impacts of disasters. Berlin: Springer Verlag, 2004: 1.

25. Rose A, Liao S Y. Modeling Regional Economic Resilience to Disasters: A Computable General Equilibrium Analysis of Water Service Disruptions. Journal of Regional Science. 2005, 45 (1): 75-112.

26. Benson C, Clay E. Understanding the Economic and Financial lmpacts of Natural Disasters. Washington DC: World Bank Publications, 2004.

27. Albala-Bertrand J M. Political Economy of Large Natural Disasters: With Special Reference to developing countries. Oxford: Oxford University Press, 1993.

28. Albala-Bertrand $\mathbf{J}$ M. The Unlikeliness of an Economic Catastrophe. 2006.

29. Toya H, Skidmore M. Economic development and the impacts of natural disasters. Economics Letters. 2007, 94(1): 20-25.

30. Hallegatte S, Dumas P. Can natural disasters have positive consequences? Investigating the role of embodied technical change. Ecological Economics. 2009, 68(3): 777-786. 